\title{
CT Number and Linear Attenuation Coefficient Variation in Hypertensive Patients with Brain Hemorrhage and Infarction Using CT Scan
}

\author{
Suresh Gnawali' ${ }^{1}$, Sheskant Aryal ${ }^{2}$ and Ananda Prasad Shrestha ${ }^{3}$ \\ ${ }^{1}$ Department of Physics, St. Xavier's College, Maitighar, Kathmandu, Nepal \\ ${ }^{2}$ Central Department of Physics, Tribhuvan University, Kirtipur, Kathmandu, Nepal \\ ${ }^{3}$ Department of Radiology and Imaging, Om Hospital and Research Centre Kathmandu, Nepal \\ ${ }^{1}$ E-mail: gnawali.suresh@gmail.com
}

\begin{abstract}
The aim of this paper is to study the variation of brain matter of Nepalese patients using CT scan. CT number and linear attenuation coefficient (LAC) of cortical bone are found largest among other brain matters, indicating the largest density. All brain matters except cortical bone show low association indicating slight changing trend with age. The cortical bone under 10 years shows low value of LAC and CT number, indicating cortical bone towards maturation whereas cortical bone shows no significant increase with age above 10 years. There is no much significant relation by gender in brain hemorrhage and infarction.
\end{abstract}

Keywords: CT image, Hounsfield unit, texture analysis, brain hemorrhage, brain infarction.

\section{INTRODUCTION}

Major innovation, X-ray computed tomography (CT), was introduced into diagnostic imaging in early 1970s. This innovation is recognized as the most significant event in medical imaging. The importance of CT is related to several of its features, including provision of crosssectional images of anatomy, availability of contrast resolution superior to traditional radiology, construction of images from x-ray transmission a "black box". The productions of images from digital data are processed by computer and can be manipulated to yield widely varying appearances (Hendee \& Ritenour, 2002).

The gray levels in a CT slice image correspond to X-ray attenuation reflecting the proportion of X-rays scattered or absorbed as passing through each voxel. X-ray attenuation is primarily a function of X-ray energy and the density and composition of the material being imaged (Ketcham, 2012).

LAC $\left(\mu_{t}\right)$ of each tissue pixel is compared with LAC of water $\left(\mu_{\mathrm{w}}\right)$ using following expression.

$\Rightarrow$ CTnumber $=1000\left(\frac{\mu_{t}-\mu_{w}}{\mu_{w}}\right) \mu_{t}=\frac{\mu_{w}}{1000}(1000+$ CTnumber $)$

When, $\mu_{\mathrm{w}}=0.191$ per $\mathrm{cm}$, then we get:

$\mu_{t}=0.000191(1000+$ CTnumber $)$ per $\mathrm{cm}$.

Water is used as reference material because its LAC is close to those of soft tissue and it is reproducible material for machine calibration. The LAC of typical bone and water are of $0.38 \mathrm{~cm}^{-1}$ and $0.19 \mathrm{~cm}^{-1}$ respectively and the
CT number of bone is +1000 (Farr \& Allisy-Roberts, 2002).

Hypertension is a condition and characterized with an abnormal increase in blood pressure where systolic blood pressure is greater than $160 \mathrm{mmHg}$ and /or a diastolic blood pressure is $95 \mathrm{mmHg}$ or greater (Segen \& Wade, 2004). Hypertension predisposes to atherosclerosis and has specific effect on particular organs of heart, brain, kidneys, and blood vessels (Waugh \& Grant, 2006).

Brain hemorrhage is known as bleeding in the brain which caused due to swell of an artery in the brain and then it bursts, which can resulted the brain cells being killed anywhere in or on the brain. CT findings of brain hemorrhage are done by clinical practice and acute hemorrhage (0-72hrs) appears hyperdense to human brain unrestricted semi liquid clot appears hypodense within the acute hematoma. Sub-acute hemorrhage (4-14 days) becomes virtually isodense with the adjacent brain parenchyma. It shows a peripheral post contrast enhancement. Chronic hemorrhage ( $>2$ weeks) appears hypodense to the adjacent brain. High attenuation within chronic hematomas is usually secondary to the re-bleeding. A target sign on post contrast image can be seen if re-hemorrhage takes place within an organizing hematoma; if re-bleeding occurs outside an organized hematoma and it can resemble with a tumorial hemorrhage (Bhargava, 2006).

The brain is prevented from receiving blood, leading to tissue damage, stroke, and possible fatality is known as a brain infarction (http://www.wisegeek.com). Acutely infracted tissue is isodense with brain initially, it then 
becomes darker (decreased attenuation) in the acute phase, returns to a more normal attenuation during the next 2-3 weeks (fogging effect), and then markedly decreases in attenuation as it enters the chronic phase. Contrast-enhanced images often show gyriform enhancement during the fogging period (Jonathan \& Allen, 2006). In this context, the objective of this paper is to find the CT number and LAC of brain matters, and also to know the relation of brain hemorrhage and infarction by age-gender along with LAC of gray and white matter by gender.

\section{MATERIALS AND METHODS}

The non-systematic prospective experimentobservational study was undertaken at the Department of Radiology and Imaging, Om Hospital and Research Centre, Kathmandu, Nepal. The experimental observations conducted during May to September, 2011. CT scanner of Siemens Company, Somatom Esprit and co-operative equipment of Om Hospital, has been selected and it conducted with fixed photon energy by keeping $130 \mathrm{kVp}$ and $260 \mathrm{mAs}$ the dependency, which is only carried out by the density of brain matters. The brain matters are of different densities, hence CT number and LAC of brain matter varies. The parameters are collected as Hounsfield Unit (HU) of white matter, gray matter, CSF, Cortical bone, ICB and infarction. In the experimental observations, 20 patients are from brain hemorrhage while 20 from brain infarction including equal number of each sex. The data are organized and then analyzed by using tabulation and diagrams. Mean, correlation, and the test of independence are used.

\section{RESULTS AND DISCUSSION}

The results of the CT number and LAC of brain matter of hemorrhagic male and female patients are presented in Table 1. It is found that in both hemorrhagic male and female brain CT number and LAC of CSF, white matter, gray matter, ICB and cortical bone are gradually in increasing order and are distinct, which indicating that CT diagnosis of brain hemorrhage is more effective. However, other brain diseases may have CT number as close as in brain hemorrhage which needs proper diagnosis. It is commonly observed that CT number of ICB ranges from 50 and reaches below 80 in the most observational cases. CT number for other brain matter does not change appreciably from that of the normal brain. This finding is similar for both male and female patients.

Table 1. CT number and LAC of brain matter of hemorrhagic male and female brain

\begin{tabular}{|c|c|c|c|c|c|c|c|c|c|c|c|c|c|}
\hline \multirow[b]{2}{*}{ SN } & \multirow[b]{2}{*}{$\begin{array}{l}\text { Age/ } \\
\text { Sex }\end{array}$} & \multicolumn{12}{|c|}{ Attenuation (HU) of X-rays with } \\
\hline & & WM & $\begin{array}{c}\mu_{\mathrm{wm}} \\
\left(\mathbf{c m}^{-1}\right)\end{array}$ & GM & $\begin{array}{c}\mu_{\mathrm{gm}} \\
\left(\mathbf{c m}^{-1}\right)\end{array}$ & CSF & $\begin{array}{c}\mu_{\mathrm{CSF}} \\
\left(\mathrm{cm}^{-1}\right)\end{array}$ & CB & $\begin{array}{l}\mu_{\text {cbone }} \\
\left(\mathbf{c m}^{-1}\right)\end{array}$ & ICB & $\begin{array}{c}\mu_{\mathrm{ICB}} \\
\left(\mathbf{c m}^{-1}\right)\end{array}$ & Inf & $\underset{\left(\mathrm{cm}^{-1}\right)}{\mu_{\mathrm{inf}}}$ \\
\hline \multicolumn{12}{|c|}{ Hemorrhagic male brain } & \multirow{22}{*}{ Nil } & \multirow{22}{*}{ Nil } \\
\hline 1 & $25 / \mathrm{M}$ & 30.4 & 0.196806 & 41.6 & 0.198946 & 9.6 & 0.192834 & 1587.0 & 0.494117 & 64.90 & 0.203396 & & \\
\hline 2 & $31 / \mathrm{M}$ & 29.0 & 0.196539 & 41.0 & 0.198831 & 10.0 & 0.192910 & 1760.0 & 0.527160 & 71.56 & 0.204668 & & \\
\hline 3 & $51 / \mathrm{M}$ & 32.4 & 0.197188 & 39.8 & 0.198602 & 11.6 & 0.193216 & 1394.0 & 0.457254 & 51.80 & 0.200894 & & \\
\hline 4 & $53 / \mathrm{M}$ & 32.0 & 0.197112 & 42.0 & 0.199022 & 2.4 & 0.191458 & 1359.0 & 0.450569 & 67.88 & 0.203965 & & \\
\hline 5 & $56 / \mathrm{M}$ & 26.8 & 0.196119 & 40.0 & 0.198640 & 11.0 & 0.193101 & 1092.0 & 0.399572 & 51.08 & 0.200760 & & \\
\hline 6 & $61 / \mathrm{M}$ & 30.4 & 0.196806 & 33.6 & 0.197418 & 10.8 & 0.193063 & 1414.0 & 0.461074 & 66.60 & 0.203720 & & \\
\hline 7 & $63 / \mathrm{M}$ & 27.0 & 0.196157 & 37.4 & 0.198143 & 7.6 & 0.192452 & 1355.0 & 0.449805 & 67.32 & 0.203860 & & \\
\hline 8 & $68 / \mathrm{M}$ & 30.0 & 0.196730 & 42.0 & 0.199022 & 8.2 & 0.192566 & 1234.0 & 0.426694 & 66.80 & 0.203760 & & \\
\hline 9 & $73 / \mathrm{M}$ & 28.0 & 0.196348 & 39.4 & 0.198525 & 5.4 & 0.192031 & 1558.0 & 0.488578 & 54.32 & 0.201380 & & \\
\hline 10 & $78 / \mathrm{M}$ & 31.4 & 0.196997 & 40.0 & 0.198640 & 8.0 & 0.192528 & 1506.0 & 0.478646 & 70.96 & 0.204550 & & \\
\hline \multicolumn{12}{|c|}{ Hemorrhagic female brain } & & \\
\hline 1 & $6 / \mathrm{F}$ & 25.6 & 0.195890 & 37.6 & 0.198182 & 3.2 & 0.191611 & 886.0 & 0.360226 & 63.04 & 0.203041 & & \\
\hline 2 & 9/F & 27.0 & 0.196157 & 38.4 & 0.198334 & 8.0 & 0.192528 & 1008.0 & 0.383528 & 54.80 & 0.201467 & & \\
\hline 3 & $22 / \mathrm{F}$ & 29.0 & 0.196539 & 41.0 & $0.198831 \mathrm{~s}$ & 7.6 & 0.192452 & 1396.0 & 0.457636 & 64.30 & 0.203281 & & \\
\hline 4 & $35 / \mathrm{F}$ & 28.8 & 0.196501 & 42.2 & 0.199060 & 10.0 & 0.192910 & 1446.0 & 0.467186 & 68.40 & 0.204064 & & \\
\hline 5 & $36 / \mathrm{F}$ & 29.8 & 0.196692 & 39.8 & 0.198602 & 11.4 & 0.193177 & 1622.0 & 0.500802 & 64.76 & 0.203369 & & \\
\hline 6 & $55 / \mathrm{F}$ & 30.8 & 0.196883 & 40.4 & 0.198716 & 11.6 & 0.193216 & 1272.0 & 0.433952 & 62.96 & 0.203025 & & \\
\hline 7 & $56 / \mathrm{F}$ & 32.0 & 0.197112 & 42.0 & 0.199022 & 12.0 & 0.193292 & 1343.0 & 0.447513 & 64.66 & 0.203350 & & \\
\hline 8 & $67 / \mathrm{F}$ & 31.0 & 0.196921 & 41.0 & 0.198831 & 11.6 & 0.193216 & 1625.0 & 0.501375 & 68.56 & 0.204095 & & \\
\hline 9 & $80 / \mathrm{F}$ & 30.0 & 0.196730 & 39.0 & 0.198449 & 7.0 & 0.192337 & 1193.0 & 0.418863 & 58.42 & 0.202158 & & \\
\hline 10 & $83 / \mathrm{F}$ & 30.4 & 0.196806 & 41.2 & 0.198869 & 9.4 & 0.192795 & 1257.0 & 0.431087 & 63.58 & 0.203144 & & \\
\hline
\end{tabular}


Table 2. CT number and LAC of brain matter of infracted male and female brain

\begin{tabular}{|c|c|c|c|c|c|c|c|c|c|c|c|c|c|}
\hline \multirow[b]{2}{*}{ SN } & \multirow[b]{2}{*}{$\underset{\text { Sex }}{\text { Age/ }}$} & \multicolumn{12}{|c|}{ Attenuation (HU) of X-rays with } \\
\hline & & $\mathbf{W M}$ & $\begin{array}{c}\mu_{\mathrm{wm}} \\
\left(\mathrm{cm}^{-1}\right)\end{array}$ & GM & $\begin{array}{c}\mu_{\mathrm{gm}} \\
\left(\mathrm{cm}^{-1}\right)\end{array}$ & CSF & $\begin{array}{c}\mu_{\mathrm{CSF}} \\
\left(\mathrm{cm}^{-1}\right)\end{array}$ & CB & $\begin{array}{c}\mu_{\text {cbone }} \\
\left(\mathrm{cm}^{-1}\right)\end{array}$ & ICB & $\begin{array}{c}\mu_{\mathrm{ICB}} \\
\left(\mathrm{cm}^{-1}\right)\end{array}$ & Inf & $\begin{array}{c}\mu_{\mathrm{inf}} \\
\left(\mathrm{cm}^{-1}\right)\end{array}$ \\
\hline \multicolumn{14}{|c|}{ Infracted male brain } \\
\hline 1 & $8 / \mathrm{M}$ & 27.0 & 0.196157 & 37.4 & 0.198143 & 10.0 & 0.192910 & 921.0 & 0.366911 & \multirow{10}{*}{ Nil } & \multirow{10}{*}{ Nil } & 15.38 & 0.193938 \\
\hline 2 & $45 / \mathrm{M}$ & 30.0 & 0.196730 & 39.4 & 0.198525 & 8.4 & 0.192604 & 1539.0 & 0.484949 & & & 14.24 & 0.193720 \\
\hline 3 & $55 / \mathrm{M}$ & 30.0 & 0.196730 & 41.2 & 0.198869 & 11.0 & 0.193101 & 1417.0 & 0.461647 & & & 15.4 & 0.193941 \\
\hline 4 & $58 / \mathrm{M}$ & 30.2 & 0.196768 & 38.8 & 0.198411 & 10.4 & 0.192986 & 1507.0 & 0.478837 & & & 15.84 & 0.194025 \\
\hline 5 & $66 / \mathrm{M}$ & 29.8 & 0.196692 & 39.6 & 0.198564 & 3.2 & 0.191611 & 1277.0 & 0.434907 & & & 13.76 & 0.193628 \\
\hline 6 & $67 / \mathrm{M}$ & 28.6 & 0.196463 & 40.0 & 0.198640 & 9.8 & 0.192872 & 1658.0 & 0.507678 & & & 14.74 & 0.193815 \\
\hline 7 & $68 / \mathrm{M}$ & 29.2 & 0.196577 & 39.2 & 0.198487 & 9.2 & 0.192757 & 1326.0 & 0.444266 & & & 15.08 & 0.193880 \\
\hline 8 & $69 / \mathrm{M}$ & 28.0 & 0.196348 & 40.4 & 0.198716 & 9.0 & 0.192719 & 1338.0 & 0.446558 & & & 14.08 & 0.193689 \\
\hline 9 & $78 / \mathrm{M}$ & 30.4 & 0.196806 & 39.6 & 0.198564 & 9.4 & 0.192795 & 1437.0 & 0.465467 & & & 15.98 & 0.194052 \\
\hline 10 & $87 / \mathrm{M}$ & 28.6 & 0.196463 & 38.0 & 0.198258 & 8.0 & 0.192528 & 1623.0 & 0.500993 & & & 14.68 & 0.193804 \\
\hline
\end{tabular}

\begin{tabular}{|c|c|c|c|c|c|c|c|c|c|c|c|c|c|}
\hline \multicolumn{10}{|c|}{ Infracted female brain } & & & & \\
\hline 1 & $46 / \mathrm{F}$ & 31.2 & 0.196959 & 40.8 & 0.198793 & 7.0 & 0.192337 & 1176.0 & 0.415616 & \multirow{10}{*}{ Nil } & \multirow{10}{*}{ Nil } & 15.20 & 0.193903 \\
\hline 2 & $55 / \mathrm{F}$ & 29.4 & 0.196615 & 38.4 & 0.198334 & 8.8 & 0.192681 & 1244.0 & 0.428604 & & & 16.30 & 0.194113 \\
\hline 3 & $58 / \mathrm{F}$ & 30.4 & 0.196806 & 40.2 & 0.198678 & 9.8 & 0.192872 & 1124.0 & 0.405684 & & & 16.52 & 0.194155 \\
\hline 4 & $62 / \mathrm{F}$ & 29.2 & 0.196577 & 40.4 & 0.198716 & 7.8 & 0.192490 & 1130.0 & 0.406830 & & & 15.02 & 0.193869 \\
\hline 5 & $70 / \mathrm{F}$ & 30.8 & 0.196883 & 40.4 & 0.198716 & 6.0 & 0.192146 & 1075.0 & 0.396325 & & & 17.86 & 0.194411 \\
\hline 6 & $75 / \mathrm{F}$ & 28.8 & 0.196501 & 39.6 & 0.198564 & 10.0 & 0.192910 & 1177.8 & 0.415960 & & & 15.84 & 0.194025 \\
\hline 7 & $79 / \mathrm{F}$ & 30.6 & 0.196845 & 40.6 & 0.198755 & 8.4 & 0.192604 & 1250.0 & 0.429750 & & & 13.56 & 0.193590 \\
\hline 8 & $83 / \mathrm{F}$ & 30.0 & 0.196730 & 38.8 & 0.198411 & 8.0 & 0.192528 & 973.0 & 0.376843 & & & 14.24 & 0.193720 \\
\hline 9 & $85 / \mathrm{F}$ & 28.0 & 0.196348 & 37.8 & 0.198220 & 11.2 & 0.193139 & 1362.0 & 0.451142 & & & 16.36 & 0.194125 \\
\hline 10 & $86 / \mathrm{F}$ & 29.0 & 0.196539 & 39.6 & 0.198564 & 10.2 & 0.192948 & 1206.0 & 0.421346 & & & 16.20 & 0.194094 \\
\hline
\end{tabular}

NOTE: SN-Serial Number, WM-White Matter, GM-Gray Matter, CSF-Cerebrospinal fluid, CB-Cortical Bone, ICB-Intracranial Bleed

Table 2 gives the brain matter variation in case of brain infarction for males and females. It is found that CT number of infarction in infracted brain ranges from more than 10 to less than 22 in most cases, it greatly resembles with the CT number of CSF in certain cases therefore careful speculation only yield proper diagnosis. These

(a)

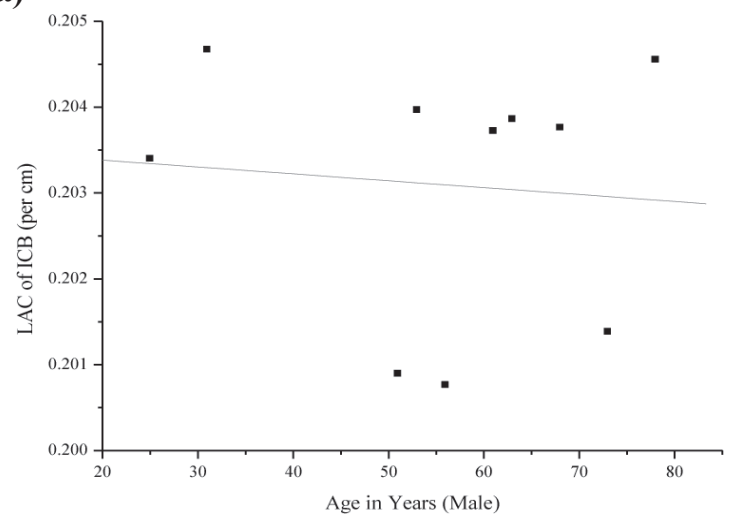

variations usually depend on how old the disease was. The CT number of ICB is nil as bleeding is absent in present case. Other brain matter variation is found insignificant as in previous case of brain hemorrhage compared with normal brain.

(b)

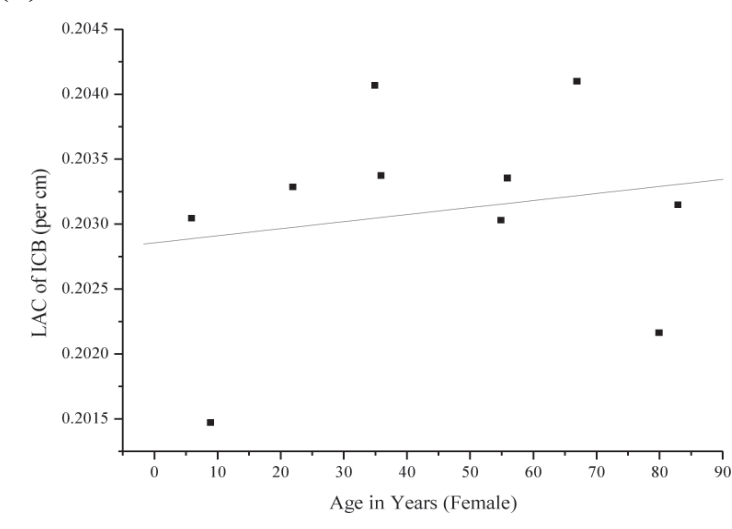

Fig 1. (a) Graph showing no significant correlation $(r=-0.09144)$ between LAC of ICB and age of brain hemorrhage male patient (b) Graph showing no significant correlation $(r=0.18962)$ between LAC of ICB and age of brain hemorrhage female patient 
Variation between LAC of ICB and age of male and female patients shows no significant association (Fig. 1). It is also seen that the correlation between LAC of ICB and age of each sex in brain hemorrhage patients is found insignificant. This result indicates that the disease can occur at any age. In both the cases the value of

(a)

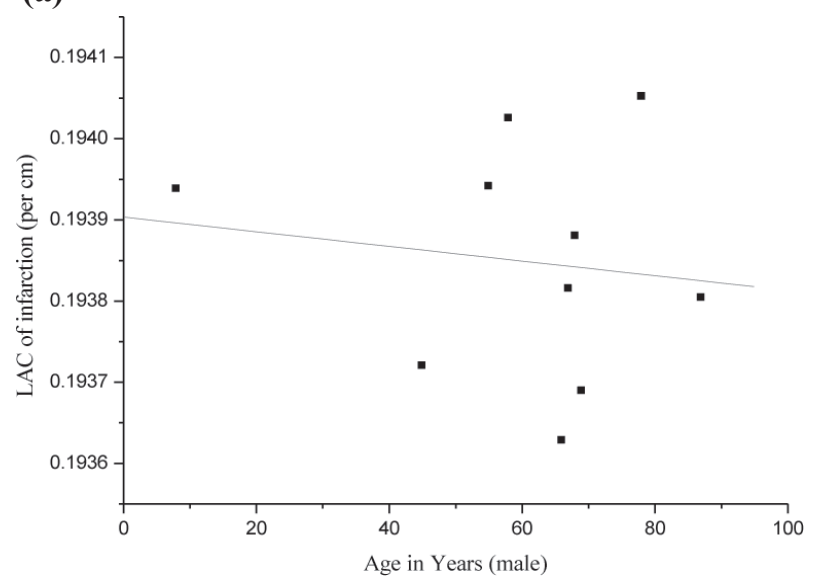

correlation coefficient is low. However, in male patients the correlation is negative while in female patients the correlation coefficient is found small but positive. Large number of patients were recorded with increasing age as risk factors like obesity, stress, consumption of more fat and others are more likely at that age.

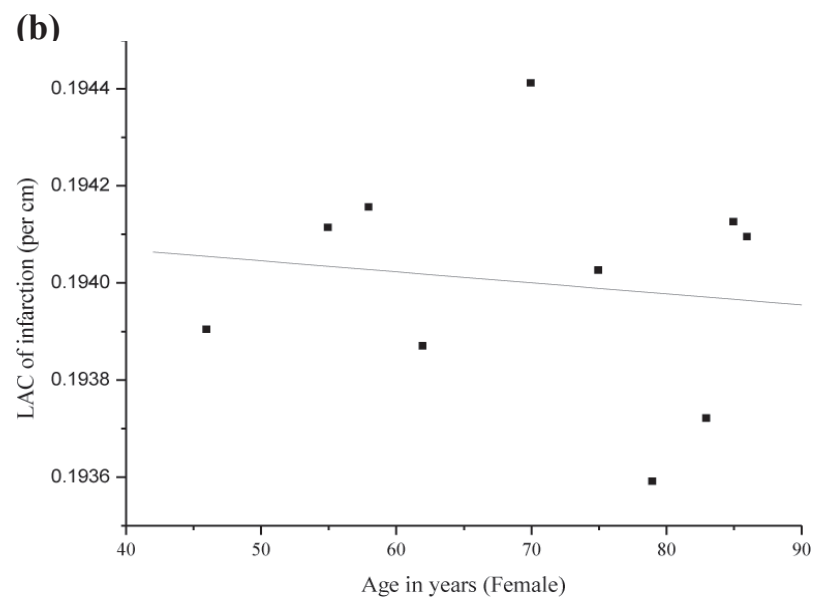

Fig 2. (a) Graph showing no significant correlation ( $r=-0.1369)$ between LAC of infarction and age of brain infarction male patient, and (b) Graph showing no significant correlation $(r=-0.13429)$ between LAC of infarction and age of brain infarction female patient

Variation between LAC of infarction and age of male and female patients' brain shows no significant association (Fig. 2). The result shows that degree of correlation is low between LAC of infarction and age of each sex in case of brain infarction patient. In both sexes correlation coefficient is small and negative. This reveals that

(a)

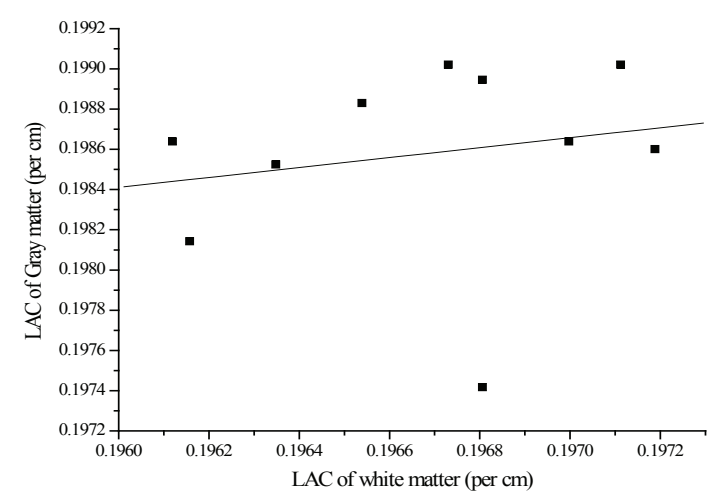

the disease is possible at any age groups of patients. However, the people of higher age are at higher risk due to sedentary lifestyle, stress and lack of physical exercise, which are usually observed less in the lower age groups of patients.

(b)

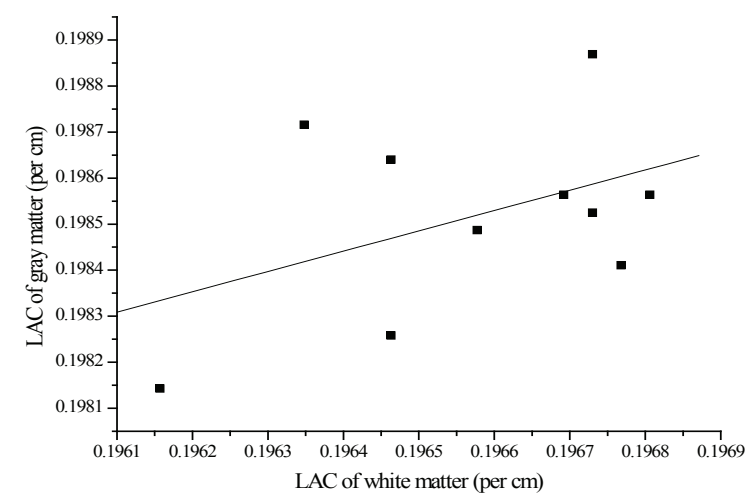

Fig 3. (a) Graph showing correlation $(r=0.19246)$ between LAC of gray matter and white matter of brain hemorrhage male patient (b) Graph showing correlation( $r=0.44186)$ between LAC of white and gray matter of brain infarction male patient

Fig. 3 shows that the variation between LAC of white and gray matter of male brain is found significantly associated for both diseases. It is also seen that there is a positive relation between LAC of white and gray matter in brain hemorrhage and brain infarction patients for male. This result equally holds in case of female patients for both the diseases. In addition to this result, the development of white and gray matter goes side by side. 
Table 3: $\chi^{2}$ test for ICB of hemorrhagic male and female brain patient and infarction of infracted male and female brain patient

\begin{tabular}{|c|c|c|c|c|c|c|c|c|c|c|}
\hline \multirow[b]{2}{*}{ LAC of } & \multicolumn{5}{|c|}{ ICB of brain hemorrhage for male and female patient } & \multicolumn{5}{|c|}{ Infarction of infracted male and female brain patient } \\
\hline & $\begin{array}{c}0.200760- \\
0.202158\end{array}$ & $\begin{array}{c}0.202158- \\
0.203720\end{array}$ & $\begin{array}{c}0.203720- \\
0.204095\end{array}$ & $\geq 0.204095$ & $\begin{array}{l}\text { Total } \\
\text { (RT) }\end{array}$ & $\begin{array}{c}0.193590- \\
0.193720\end{array}$ & $\begin{array}{c}0.193720- \\
0.193938\end{array}$ & $\begin{array}{c}0.193938- \\
0.194052\end{array}$ & $\geq 0.194052$ & $\begin{array}{l}\text { Total } \\
\text { (RT) }\end{array}$ \\
\hline Male & 3 & 1 & 4 & 2 & 10 & 2 & 4 & 3 & 1 & 10 \\
\hline Female & 1 & 7 & 1 & 1 & 10 & 1 & 3 & 1 & 5 & 10 \\
\hline Total(CT) & 4 & 8 & 5 & 3 & $\mathrm{~N}=20$ & 3 & 7 & 4 & 6 & $\mathrm{~N}=20$ \\
\hline \multicolumn{6}{|c|}{$\chi^{2}=7.63$} & \multicolumn{5}{|c|}{$\chi^{2}=4.14$} \\
\hline
\end{tabular}

Table 3 presents the association between male and female patients in case of brain hemorrhage and infarction. The insignificant chi-square values suggest that there is no association between LAC of infarction of infracted male and female brain. This shows that there is no evidence of the occurrence of hemorrhage in male, which linked with occurred in female. This result also holds good for the patients of brain infarction for both sexes.

The ICB and infraction can be detected easily through
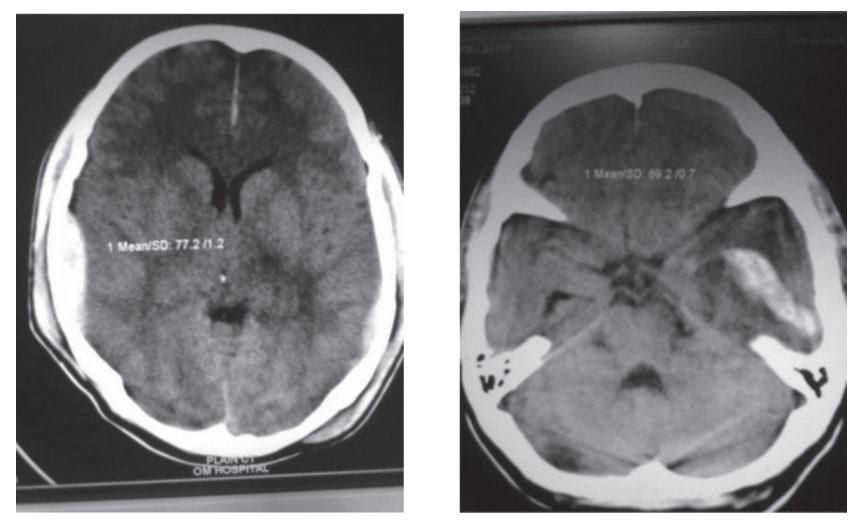

(a)

(b)

Fig 4. Hemorrhagic brain (a) (35/F) and (b) (25/M)

Fig. 5(a) shows the CT image of 75 years of female patient with brain infarction. The Fig. 5(b) refers to that of 45 years male patient of the same disease. The texture analysis of CT image showing decrease in attenuation is represented by white spot in each image where the CT number as well as standard deviation measured is also depicted. The variation in two images is usual as the portion of blockage, history and duration of disease may differ.

The range of CT number and LAC of brain matters mentioned lies clinically accepted range and is also in agreement with similar studies conducted by Reddinger (1998), Mishra (2009) and Silwal (2010). The CT number and LAC of cortical bone are found largest among other brain matters indicating largest density. It is found that
CT technique. Some CT images out of large observations are depicted in Figs. $4 \&$ 5. Fig 4(a) represents the CT image of hemorrhagic female patient of age 35 years whereas Fig. 4(b) shows the CT image for male patient of age 25 of the same disease. Texture analysis of CT image enables us to identify the CT number of brain matter. The CT number and standard deviation taken during the observation are shown in the image pointing by white spot. The bleeding in the brain is clearly seen in the Fig. 4.

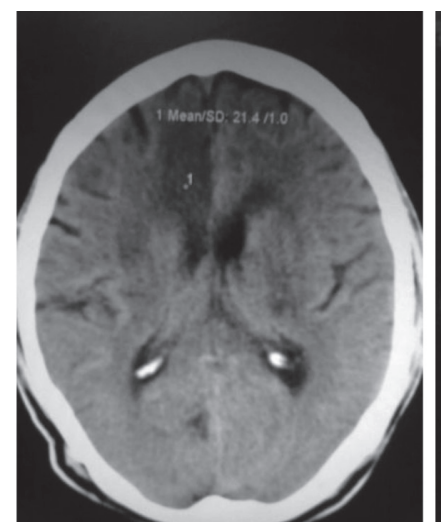

(a)

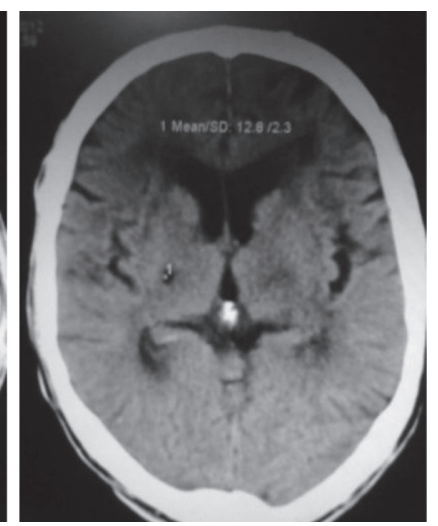

(b)
Fig 5. Infracted brain (a) (75/F) and (b) (45/M)

all brain matters except cortical bone shows lower association indicating slight change trend with age. The cortical bone associated with age under 10 years shows low value of LAC and CT number indicating cortical bone towards maturation. Above 10 years, cortical bone shows no significant increase with age in male whereas in female slightly decreasing value of cortical is observed. These findings are found consistent with the several findings elsewhere (Reddinger, 1998; Mishra, 2009; Silwal, 2010; Cosgrove et al. 2007; Good et al. 2001; Koenraad et. al. 2001).

The white and gray matter of brain are found to be significantly associated. The hemorrhagic patients by gender are found significantly different where male patients shows lower association than that of female 
patients. Indeed brain infarction patients showed similar results for gender, however; gender differences in size vary by more specific brain regions. Studies revealed that men have a relatively larger amygdalae and hypothalamus whereas women have a relatively larger caudate and hippocampi. Women have a higher gray matter as compared to that of men but men have a higher white matter and cerebrospinal fluid as compared to that of female. Indeed, high variability between individuals is well established elsewhere (Cosgrove et al. 2007).

The significant dynamic change is well observed in brain structure through adulthood and aging with substantial variation between individuals (Good et al. 2001). It is also showed that men had a steeper decline in global grey matter volume, although in both sexes, which varied by region with some areas exhibiting little age effect. Further overall white matter volume does not appear to decline with age, although there is variation between brain regions. In fact, the discrepancy observed is accounted as from the head circumferences, which do not change significantly through childhood, but increase is due to mostly to an increase in skull thickness, not in brain size (Koenraad et. al. 2001). The brain is also found to be 12 per cent larger for male on average as compared to that of female where the difference is statically significant even controlling height and weight. The study also conducted shows that woman has 4.3 per cent higher gray matter content than that of men. The gray matter gradually loosed due to ageing, however; CSF volume has found to be lower in female with age as compared to that of male.

\section{CONCLUSION}

The present paper concludes as follows:

- The CT number and LAC of brain matters observed from this study are in agreement with clinically accepted range.

- ICB is only found in hemorrhagic brain where infarction is completely absent and infarction is only found in infracted brain where ICB is entirely absent.

- There is low degree of association between CT number of brain matters and age but the association is high between age and CT number of cortical bone. However it is found nearly constant in male with increase in age and low in child under age of 10 years irrespective of the sex.

- The association is found high in the development of white and gray matter whereas CT number of CSF is found slightly decreasing with age for both sexes.

- Insignificant association is found individually in the CT number and LAC variation of brain matters of brain hemorrhage and brain infarction.

\section{ACKNOWLEDGEMENTS}

Authors are thankful to the Imaging Unit of Om Hospital and Research Center for providing necessary Data for this paper.

\section{REFERENCES}

Bhargava, S. K. 2006. CT Differential Diagnosis. Jaypee Brothers Medical Publishers (P) Ltd, New Delhi, India, 76p.

Farr, R.F. and Allisy-Roberts, P.J. 2002. Physics for Medical Imaging. Elsevier Science Limited, 111p.

Hendee, W.R. and Ritenour, E.R. 2002. Medical Radiation Physics. Fourth edition, A John Wiley \& Sons, Inc. Publication 258- 262.

http://en.wikipedia.org/wiki/Brain_size\#refCosgrove.

http://en.wikipedia.org/wiki/Brain_size\#refGood.

http://serc.carleton.edu/research_education/ geochemsheets/techniques/CT.html\# (Richard, K. 2012).

Jonathan, H.B. and Allen D. E. 2006. Cerebral infarction diagnosis by computerized tomography: analysis and evaluation of findings, how far have we really come? AJR 186:611-612.

Koenraad, J.V.L. and Rudi A.D. 2001. Brain Perfusion SPECT: Age and Sex-related Effects Correlated with Voxel-based Morphometric Findings in Healthy Adults.

Lee, W. G. 2007. Principles of CT and CT Technology Department of Radiation Therapy and Medical Physics, Hartford Hospital, Hartford, Connecticut T*. J Nucl Med Technol 35: 125-127.

Mishra, I.K. 2009. A Study of Computerized Tomography Image Reconstruction and Calculation of Linear Attenuation Coefficients of Human Brain Matters. M.Sc. Dissertation, Tribhuvan University, Kathmandu, Nepal.

Reddinger, W. 1998. CT Image Quality Outsource Inc.

Segen, J.C. and Wade, J. 2004. The Patients Guide to Medical Tests. Second Edition, Viva Books Private Limited, New Delhi 78-140, India.

Silwal, U. 2010. Study of Post-Traumatic Normal and Abnormal Brain with the Calculation of Linear Attenuation Coefficient of Brain Matter using helical 8-Slice CT Scan. M.Sc. Dissertation, Tribhuvan University, Kathmandu Nepal.

Waugh, A. and Grant, A. 2006. Rose and Wilson Anatomy and Physiology in Health and Illness. Tenth Edition, Churchill Livingstone Elsevier, Edinburgh, UK 115-181. 